\title{
Women Working in the IT Industry: Challenges for the New Millennium
}

\author{
Liisa von Hellens (E-mail: 1.vonhellens@griffith.edu.au), Griffith University, Australia \\ Sue Nielsen (E-mail: s.Nielsen@griffith.edu.au), Griffith University, Australia \\ Jenine Beekhuyzen (E-mail: jenine@cit.gu.edu.au), Griffith University, Australia
}

\begin{abstract}
Despite increased female participation in the workforce, including some non traditional areas such as law and medicine, female participation in the Information Technology (IT) industry is declining. A longitudinal study (WinIT) commenced in 1995 has explored Australian student's and working women's perceptions and experiences, and the factors which have influenced them to enter and persist in the IT field. This paper reviews recent research and describes the latest results from the authors' study of professional women in the Australian IT industry, focusing on the contradictions in the way that women represent their experiences. These contradictions indicate that polarised views of gender in the IT workforce are being undermined, but also that IT personnel have difficulty reconciling their personal and work lives and coping with the rapid rate of change in the industry. The implications for human resources management in the volatile IT industry as well as some possible solutions to the problem are also discussed.
\end{abstract}

\section{Introduction}

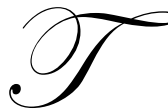

wo concerns have preoccupied Information Technology (IT) personnel research in the last two decades; the shortage of qualified IT personnel and the declining participation of women in the IT industry. Despite a noticeable, although small, rise in female participation in the traditionally maledominated professions of science, engineering and medicine, there has not been a corresponding trend in the information technology sector. By the start of the last decade, the proportion of females in the IT workforce was beginning to decline in most western countries (von Hellens, et al. 2000). At the end of 1999 women represented just 29 percent of the workforce in the US technology sector, down from 40 percent of the workforce in 1986 (Council of Economic Advisors 2000).

Despite the recent dot.com crashes, the demand for IT professionals remains high with continuing gaps forecast in specific skills areas (Burton 2002). As IT becomes more embedded into organizational infrastructure and the rate of IT innovation poses new challenges for business managers, it becomes more critical to secure a reliable, highly qualified pool of personnel who can understand new technologies and their potential applications (Feeny and Willcocks, 1999).

Declining female participation is therefore viewed as an economic problem, as well as an equity issue (Johnson and Miller 2002). A recent US report asserted that "if the number of women in the IT workforce were increased to equal the number of men, even the tremendous shortages of IT workers noted in the ITAA studies could be filled. However, according to the Department of Commerce, only 1.1 percent of undergraduate women choose IT-related disciplines as compared to 3.3 percent of male undergraduates." (Freeman and Aspray, 1999).

This paper provides an overview of research into this problem of female participation in the IT industry, including the WinIT research project commenced by the first two authors in 1995. The paper discusses in more detail recent findings from the authors' study of professional women in the Australian IT industry, focusing on the contradictions in the way that women represent their experiences. These contradictions indicate that polarised views of gender in the IT workforce are being undermined, but also that IT personnel continue to have difficulty reconciling their personal and work lives and coping with the rapid rate of change in the industry. Finally, the implications for human resources management in the volatile IT industry as well as some possible solutions to the problem are also discussed. 


\section{Background}

The shortage of women in IT has been vividly characterised as a shrinking 'pipeline'. Camp (1997) used this phrase to refer to the small and declining number of women who continue IT related studies after leaving school and the continuing decline through post graduate studies and academic appointments. Other studies have indicated that the pipeline shrinks even earlier, in the years between junior and senior high school (for example, Meredyth et al, 1999) when girls' interest and confidence in the use of computers declines markedly. The implications of this shrinking pipeline are that women find themselves increasingly in the minority at study and work and find few role female models amongst senior professional and academic staff. Research has shown these are amongst the significant factors which inhibit female participation, as discussed in the next section.

The problem is considered important and has generated considerable research (Ahuja 2002). In the USA, a National Science Foundation (NSF) funded project (Gürer and Camp, 2002) attempted to bring all research into the declining participation of women in computer science education together and help provide a coherent direction for future work. In their work, a large number of articles was gathered and processed on the topic of women in computing and the shrinking pipeline.

Research which attempts to explain this decline and suggest solutions, is complicated by a lack of clarity in the definitions of the IT industry and IT personnel, made even more difficult by the rapid rate of change in the industry. Definitions produced by industry organisations (such as the Australian Bureau of Statistics) do not necessarily reflect the experience of people working in the industry. Furthermore, staff in the IT industries differ from other complex, highly paid occupations. Although the IT industry generally hires a significant number of university graduates, figures from the NSF show that in 1999 less than 40\% of people whose principal occupation is IT, held computer/information science degrees (Wardle and Burton, 2002). The industry also lacks institutionalised forms other than prescribed professional education, such as membership of associations, defined career paths and professional sanctions, which are characteristic of other complex occupations such as law, medicine, accountancy, architecture and engineering (Encel 1970).

The research discussed in this paper acknowledges this difficulty. Although our study of high school and university students was limited to the recruitment of students into traditional IT degrees, our research into women working in IT revealed that they come from a diverse set of backgrounds, with different educational qualifications and work histories. They proposed aptitudes and skills rather than specific professional education as important for success in the industry. They see the IT industry as diverse, offering many different options for work and careers.

The problem of female recruitment and retention is complex and multidimensional and some of these factors are increasingly seen as problematic for men and as well as women in the industry. In order to deal with this complexity, the WinIT research project has taken several perspectives, reflecting the multidimensional nature of the problem (von Hellens and Nielsen 2001). The project has surveyed and interviewed high school students as well as undergraduate and post graduate IT students. Interviews have been carried out with high school teachers, vocational guidance counselors, IT academics and professionals in the IT industry. This paper builds on recent work (Nielsen et al, 2003; Trauth et al, forthcoming; von Hellens et al, 2003), focusing on the recruitment, retention and success of women in the IT industry, in relation to their perceptions of gender and IT work.

\section{Ongoing Research}

Research into gender and IT has taken two major approaches; that men and women are inherently different or that gender differences are primarily socially constructed. The inherent differences approach comprises two streams of research looking at gender differences in the acceptance of technology. For example, Venkatesh and Morris (2000) and Venkatesh et al. (2000) investigate gender differences in computer anxiety and aptitude, concluding that these differences explain lower adoption rates by women. A similar approach is taken in studies of female students, which treat women as an undifferentiated category and focus on the psychological characteristics that restrict, rather than encourage, them to undertake IT studies (Brosnan \& Davidson, 1996). 
A second stream of research within the inherent differences approach is represented by Spender (1995) who holds that increased female participation in the IT industry would transform and improve information technology design and use.

Our approach in the WinIT project views gender and technology as socially constructed and seeks to explore the masculinisation of the IT domain and the way that women cope with the social embededness of IT institutions. Particularly, the research has focused on the cultural and gender factors affecting female recruitment (von Hellens and Nielsen 2001). A conceptual model of the identified factors was developed and such an approach was found to be useful in examining the situation with relation to high school students and university students (Nielsen, et al. 1999a). The research considers factors such as media representations of IT, peer, school and parental influences. Both male and female students lacked information about IT work and education and did not demonstrate any understanding about the nature of IT work. Overwhelmingly the students perceived IT as a masculinised domain and the female students mainly saw IT courses as boring and difficult. The male dominated study environment at university contributed to female attrition in IT courses.

Since 1999 our research has been extended to women working in the IT industry and IT academia, where the significance of informed choice is more evident (Pringle et al. 2000; Trauth, Nielsen and von Hellens 2000; von Hellens et al. 2000). These women have resisted in some way the influences, which discourage young women from entering IT and have persisted in developing their IT careers. This paper presents early attempts to reexamine texts of professional women's interviews using some concepts from structuration theory. These concepts were initially established as relevant through a rereading of the interviews (von Hellens et al, 2003).

\section{Research Approach}

To understand the complexity of women's experiences in the IT industry, a structuration approach to has been adopted to explore the factors which inhibit and enable women to enter and succeed in the IT industry. Within the information systems research discipline, there is a growing interest in using particular concepts from structuration theory (Jones 1999), focusing primarily on the nature of technology and its relationship to human agents in information systems development and use. We have extended this application to the problem of the relationships between the IT education and commercial industries, social perceptions of IT education and work and the human resource requirements of the IT industry.

We are using the Giddens theory of structuration to analyse the changing relationship between social structures (the IT education and commercial industries) on the one hand, and human agency (students and IT professionals) on the other hand. Although there are many critiques of Giddens' theory of structuration, Halford and Leonard (2001) suggest that Giddens offers "considerable promise for the development of fuller understandings between gender, power and organisation". In particular, we are interested in the formation of identity amongst women working in IT who have "stepped outside into social settings in which the only available identities were those offered by male stereotypes" Giddens, 1991, p216).

Most of the studies in the very large body of literature on the demand for IT skills take a positivist approach. However, from a structuration theory point of view, demand for IT skills cannot be treated as a matter of social fact, but is implicated in the structuration of the IT industry, and reinforced or challenged by industry participants.

The importance of operating within a male domain, including the extent of outside-work socializing with male colleagues as necessary for career progression has been identified previously (von Hellens, Nielsen and Trauth 2001). The implication is that while women have been socialized away from IT, the IT field has been constructed as a masculine domain. This follow-up study by the collaborating authors in 2000 (Trauth, Nielsen and von Hellens 2000) enabled a deeper exploration of the current position of Australian women working in technical positions in the IT industry.

This paper revisits the interview data discussed in the Trauth, Nielsen and von Hellens paper (2000) and in the von Hellens et al papers $(2000 ; 2001)$ from the perspective of structure and agency. As an initial attempt to uncover the sense of identity of the women interviewed we discuss the interview data in terms of the concepts of duali- 
ty and dualisms, routinisation and interpretive schemes and signification. The focus is on structures of signification since the research has so far collected only interview and survey data. To use the other dimensions of Giddens' duality of structure it would be helpful to undertake observation and the examination of documentation to identify how domination and legitimation occurs through the use of power and sanctions.

\section{Data Collection and Analysis}

Interviews were conducted in 1999-2000 with thirty-two (32) female and two (2) male IT professionals working in technical areas of the Australian IT industry. The interviewees represent a range of ages, employment sectors, educational backgrounds and ethnic backgrounds. The males were interviewed primarily to provide insight into the female experience.

The data collection was a collaborative effort between von Hellens and Nielsen, Australian-based researchers, and Trauth, a US-based researcher.

Semi-structured open-ended interviews of approximately 90 minutes in duration allowed interviewees to express their personal views and discuss their individual experiences in the Australian IT industry. Four main areas were covered, including demographic information, personal history, general questions about gender and IT, and recommendations regarding how society, the IT profession and educational institutions might address the gender imbalance in IT (von Hellens, Nielsen and Trauth 2001). The interviewed women are not a random sample, they were identified as being active in Women in Information Technology associations and from a data base of women working in software engineering and systems development roles, whose companies had recently participated in software quality assessments. These women are both the subjects of our study and informed observers of the skills issues faced by women in the industry.

The respondents were IT practitioners working in a range of levels at a range of industry sectors and academics in IT faculties. The female subjects offered two perspectives on the topic; their experiences of entering and progressing in the IT field, and helping other women enter and succeed in IT.

Initial sorting and analysis of the interview data was carried out with the aid of NUD*IST, an Australian qualitative software application. NUD*IST is an acronym for Non-numerical Unstructured Data, Indexing, Searching and Theorising (QSR 1997). The software allows the researcher to connect a 'term' and a 'concept' which allows for enriched indexing and takes into account that expressions cannot be taken at face value, and must be related to their context (Klein and Myers 1999). The systematic approach to indexing and searching proved helpful and supported communication between the researchers. However, in this study the software did not assist in theorising at this point. Discussion of the use of the software in this project can be founded in Beekhuyzen et al (2003a, 2003b).

After the initial coding of interview data at nodes, the data was searched manually for distinctive patterns of text, using methods from discourse analysis (Fairclough 1992a, 1992b, 1997); in other words we looked for the meaning of discourse patterns within the context of the total data set and in relation to contextual factors. Significant contradictions/oppositions were found in the data, as detailed in the next section.

An examination of our interview data using concepts from structuration theory shows that a number of dualisms provide the interviewees with interpretive schemes through which they can interpret and make sense of their working lives. Such dualisms may provide ontological security as representations of the routines which women in the IT industry enact in their daily activities.

However, a further consideration of the data revealed contradictions in these dualisms, indicating that these polarised views of women and IT work are being undermined by women in the IT industry. This is in line with Giddens' notion that "human agents never passively accept external conditions of action, but more or less continuously reflect upon them and reconstitute them in the light of their particular circumstances" (Giddens, 1991, p.175).

\section{Duality and Dualisms}


Central to Giddens' structuration theory is the notion of duality (Giddens 1984). In keeping with modern trends in sociology, Giddens rejected the notion of outright dualism, in which the fundamental forms of things are viewed as of two contrasting irreducible types (for example nature and nurture) and duality may thus be considered as an attempt to resolve the 'agency/structure debate' (Walsham and Han 1990). This debate concerns the paradox of social reality whereby "the properties of the elements of social phenomena obtain many of their characteristics from the larger phenomena of which they are a part, while the larger entities obtain their characteristics mostly from the relations between the parts of which they are composed" (Cohen 1968).

Structuration is therefore an approach to understanding social institutions "that replaces the dualisms of social theory with a duality of reciprocal interdependencies" (Boland 1996). Giddens criticised contemporary sociology for treating the relationship between the individual and society as a dualism, in which individual and society are separable, and for producing social theories which focus on one side of the paradox; functionalism for example regarding the individual as produced and determined by society, whereas interpretivism regards the individual as the producer of social reality. In contrast to dualism the notion of duality proposes a dialectical interaction between conceptual pairs with no claim that that these concepts are ultimately irreducible. Thus Giddens' approach is to propose a duality of structure in which "the structural properties of social systems are both the medium and the outcome of the practices that constitute these systems" (Giddens 1979).

Taking this point of view, the authors were surprised to identify a number of dualisms in the way women typically represent their work experiences in the IT industry (summarised in Table $1 \& 2$ ). This paper briefly explores some of these dualisms and how contradictions in their expression seem to indicate that polarised views of women in IT are being modified. In other words, we view the dualisms as social structures which influence individual actions both in an enabling and constraining manner, but which over time may be reinforced, modified and transformed by individual actors.

Writers in women's studies have shown how such dualisms are constructed (Barrett 1992) depending on prevailing social tendencies (such as the dualism between individual and society as a product of the Enlightenment). They have also shown how the notion of dualism enables the promotion of one type of experience over the other so that dualisms often consist of unequal conceptual pairs, (such as active/passive, public/private) associated with gender and power (Porter 1991).

A dualistic approach to the problem of female participation in IT can be seen in much of the literature, particularly that proposing the idea of inherent differences as discussed earlier (e.g. (Venkatesh, Morris and Ackerman 2000).

The dualisms in Table 1 represent IT work and skills as a set of either/or propositions. To be good at programming infers lack of communication skills. Technological knowledge is distinct from business knowledge. Private/ home concerns and work issues are separable, as are intuition and analysis.

The dualisms in Table 2 represent skilled IT work and gender as a set of either/or propositions, but when these are examined further, certain contradictions emerge. To be a woman means having good communication skills, but not assertiveness, networking and political skills. To be interested in continuous learning and rapid change also infers masculinity. Having a broad perspective is viewed as a feminine trait, but so also is attention to detail, even though women view themselves as having lesser technical skills.
Table 1: Dualisms in IT work

\begin{tabular}{|l|}
\hline Dualisms of skills and attributes \\
\hline Home/work \\
\hline IT industry/career certainty \\
\hline Intuition/analysis \\
\hline Programming/communication \\
\hline Technical/soft skills \\
\hline Solving problems/communication \\
\hline Technology/business and management problems \\
\hline
\end{tabular}


Table 2: Gender Specific Dualisms in IT work

\begin{tabular}{|l|c|c|}
\hline \multicolumn{1}{|c|}{ Issue } & Masculinity & Femininity \\
\hline Home responsibilities & - & + \\
\hline Soft skills & - & + \\
\hline Attention to detail & - & + \\
\hline Broad perspective & - & + \\
\hline Continuous learning and rapid change & + & - \\
\hline Assertiveness & + & - \\
\hline Communication & - & + \\
\hline People focus & - & + \\
\hline Noisy vocalism & + & - \\
\hline Political skills & + & - \\
\hline Networking & + & - \\
\hline Left brain & + & - \\
\hline Programming & + & - \\
\hline Technical skills & + & - \\
\hline
\end{tabular}

\section{Discussion of Dualisms}

\subsection{Hard versus Soft Skills}

One of the most interesting dualisms is the separation of soft and hard skills, not only in terms of their association with women and men, but also in terms of how they are learned and valued. It is assumed that the soft skills of communication and organisation are learned along the way, whereas technical skills require formal education. This is despite the fact that most employers value soft skills highly (Feeny and Willcocks, 1999) and recommend that the relevant training is provided in undergraduate computer science and IT degrees.

However, what constitutes soft and hard skills is quite ambiguous. Although women represent communication and people skills as feminine attributes, political skills, networking and the ability to be 'noisily vocal' about accomplishments and needs are seen as masculine skills.

\subsection{The Dualism of Home and Work}

Another frequently occurring dualism is that of home/work and private/public life. This dualism is reinforced by women's choices to delay or not have children and their need to accommodate their working lives to their private responsibilities and vice versa. This is obviously not unique to the IT industry but the women interviewed perceive that it presents different problems where the majority of the work force is male and is not presented with this conflict. The workload associated with the need to keep up with the rapid rate of technical change and innovation is seen as difficult to reconcile with family responsibilities and makes women apprehensive about taking even short breaks from their careers, for example for maternity leave. This apprehension is supported by Australian data which shows that in IT (as well as other professions) women with children earn less than their childless counterparts (Megalogenis, 2003).

\subsection{Continuous learning and rapid change}

This relates to the dualism of family and work with women identifying their family responsibilities as limiting the amount of time they could devote to work and to keeping up to date. One of the interviewees stated strongly that she would not encourage her daughter to work in the IT industry because of the strain entailed in dealing with the increasingly rapid rate of technological change.

Gallivan (2003) cites a study (Gewirtz and Lindsey, 2001) in which 65\% of the respondents surveyed experienced "moderate to high stress/anxiety regarding the rapid rate of change" (p.13). Moreover Gallivan's survey 
found that "women's perceptions of being stressed/overworked were positively associated with the total amount of change in the workplace, but for men there was no such relationship" (Gallivan, 2003, p.19)

WinIT research into the learning environment of IT degree programmes (Nielsen, von Hellens, Greenhill, Halloran \& Pringle, 1999) indicated that women's attitude to change and the need for continuous learning is complicated by their participation in male dominated group work. Although many female students expressed confidence in their ability to succeed and saw no difference between themselves and the male students, they were subject to continuing disparagement. As indicated above, the soft skills were rated lowly and women were often assigned to such tasks (for example, documentation and client liaison) within the final year IT project. Most interestingly, although women were represented by many male students and some instructors and indeed perceived themselves as less competent in certain areas (such as programming), this was not supported by their performance where they often outranked the more confident male students.

This dualism is typical of the complexity of research in this area. Trauth (2002) pointed out that individual differences mean that women cope with these challenges in diverse ways. Our research also has shown that women perceive themselves as flexible; "women adopt and adapt very well, because we're used to making do." (von Hellens et al 2000). However, our studies of high school students (Nielsen et al 1999a) also indicated that many students observing the work patterns of their parents are discouraged from entering an industry where stress levels are very high.

\subsection{Dualisms and the Division of Labour}

Despite the recent work on new IT enabled organisational forms, the interviews of professional women confirmed that without exception they perceive their workplaces and career paths in the IT industry in terms of traditional work specialisations. The dualisms referred to above reflect a traditional division of labour into hierarchies of skills, associated with gender, power and authority. For example, some interviewees reported being assigned to the more people oriented activities even when their performance in technical tasks was satisfactory or even superior to some of their colleagues.

These hierarchies are reinforced through award systems and management evaluation criteria, which purport (claim) to be objective and equitable but which "reflect entrenched managerial values" (Acker 1990 p.149). Responsibility and complexity are defined according to existing social practices; hence the undervaluing of many femininised occupations such as nursing and child care which take responsibility for human lives but which are assumed not to require the same level of training as a profession requiring more 'hard' skills, such as medicine.

The gendering of IT work in this regard seems to have two consequences, as revealed in the interviews. It requires both men and women to 'adapt' to a masculinised domain, and it discourages many women and men from choosing IT as a field of study or career. Both the men and women interviewed indicated that they found the working arrangements and valuing of specific skill sets in the IT industry difficult.

\section{Routinisation and Interpretive Schemes}

The women interviewed expressed these dualisms in a taken for granted way. In structuration theory, the habitual, taken for granted nature of everyday activities is called routinisation; according to Giddens "the predominant form of day-to-day social activity ... In the enactment of routines agents sustain a sense of ontological security" (1984, p282). Moreover, routine is "integral to the continuity of the personality of the agent ... and to the institutions of society" (Giddens, 1984, p.60).

The unselfconscious reference to and representation of traditional dualisms allows women to operate without continual self-consciousness or anomie about the nature of the work. Anomie (Lehmann 1994) may exist where there is a conflict between personal goals and the availability of structures to support those goals, or where there is uncertainty about organisational values. In an area such as IT which is rapidly changing and which presents its professional workforce with continual challenges (including the recent dot.com crashes) the need for the ontological security provided by routinisation would be particularly strong. 
The dualisms expressed above may be viewed within structuration theory as the interpretive schemes through which signification is achieved. Interpretive schemes are "the stocks of knowledge that human actors draw upon in order to make sense of their own and others' actions" (Walsham and Han 1990 p.54). Giddens' concept of interpretive schemes is useful in showing how these women deal with the contradictions in the way they conduct their daily working lives, "making that conduct appear rational, understandable and accountable to self and other" (Boland 1996 p.693).

The emergence of contradictions points to the possible transformation of structures of signification. In structuration theory interpretive schemes are not immutable or monolithic. The meaning of particular expressions such as 'communication' needs to be interpreted within the social context. (Giddens 1979) For example, many of the women interviewed identified networking skills as an instinctive skill at which men excel and which provides them with an advantage. Male networking is carried out not only formally but also informally through common/social interests such as sports, after work drinks sessions and so on, whereas women were more likely to go home after work and take on household and family duties. However, more recently women are developing networks through formal purposeful activities such as women in IT associations. One interviewee saw this as a means for enabling women to utilise their natural assets, 'It's all sharing and giving and more so than with guys'.

\section{Issues}

Our use of structuration theory has revealed other problems in studying female participation in the IT industry. To understand the production and reproduction of social structure requires a longitudinal study but the rapid rate of change in the industry including high staff turnover make this difficult. Without a longitudinal study it is difficult to identify how individual agents reinforce, modify or transform institutionalised traditions within the IT industry.

The role of individual women in reinforcing, modifying and transforming the social structures is therefore difficult to identify. As individual actors they perceive that they have overcome barriers and succeeded in the industry. Several of the interviewees revealed they had to adopt ways of working that were not common to most women. Women who have successfully proceeded to higher managerial positions in the IT industry have adapted to whatever was needed to become part of the corporate culture. The women who are in management positions feel they possess characteristics typically considered masculine, such as being logical, task-oriented and assertive, and not perceiving themselves as victims. They talk about themselves as different from other women they know, indicating that they are challenging the dualism of gender.

These women consider that they possess key skills for the next millennium. However, it is not clear to what extent this constitutes the 'sequestration' of experience, which serves as a coping mechanism (Giddens, 1991) but which increases stress levels when events threaten the carefully constructed sense of identity. Trauth et al (forthcoming) identified three types of responses to the masculinity of the IT workplace; those who "didn't admit to operating on an uneven playing field" although they indicated that trying to balance family and work had contributed to slower career progression; those who accepted their situation as "simply the way things were" and those who were angry about their experiences. As indicated above, difficulties experienced by women at work provide negative role models for young women contemplating a career in IT.

\section{Implications for IT Human Resources Management}

We have identified several problems in researching female participation in the IT industry; the rate of change; the lack of definition of qualifications and occupations within the industry, as well as the small number and diverse nature of the women working in IT. We maintain that women cannot be treated as an undifferentiated category which is the approach taken by the inherent differences stream of gender research. Instead we are attempting to map the complexity of the industry and its personnel.

It is probably axiomatic to state that if the percentage of women entering IT increases then this problem may resolve itself as more role models are available and the work place is reconfigured to take into account wom-

en's desired working patterns, including the accommodation of family life. However, despite the wide variety of 
programmes developed to encourage and support women in IT, the participation rate has not risen. Such programmes include mentoring, providing role models in the form of seminars etc., by female students and professional women, support groups in schools and universities and the provision of more accurate information via vocational guidance officers. More empirical research needs to be carried out to investigate the effectiveness of these strategies.

Several other areas appear promising, including investigation into the effects of industry practices on staff recruitment and turnover, and the recruitment and training of staff qualified in other areas since these employees already comprise a large percentage of the IT workforce.

The level of stress associated with rapid change in the IT industry is already a feature of other workplaces, so understanding how to help employees deal with this would provide benefits to other industries as well.

During the interviews we were conscious that, as with all social science research, this study involves what Giddens refers to as 'the double hermeneutic' (Giddens 1982 p.11-13). In other words, subjects can take up and reject or reaffirm the research on Women in IT. In this way research projects themselves may help to bring about change as more interviewees consider the implications of the questions they are asked. The significance of support groups such as professional women's associations similarly encourage women to reflect on their experiences and devise strategies for supporting their female colleagues.

\section{Conclusion}

Overall, the participation of women in IT remains low and this is a matter of concern both for equity and economic progress. This paper reviews some of the contextual influences that may contribute to the declining participation, as well as some of the factors that complicate this issue. The declining interest in IT degrees and the fact that many people enter the IT workforce via other qualifications indicate that traditional IT education is not very successful in attracting either the quantity or quality of students required to meet workforce needs. This is despite the fact that IT salaries compare well with other professional salaries and are superior to most traditional female occupations (Megalogenis 2003). An often the hostile environment at university and in the workplace reinforces this problem. Current IS research considers some of the difficulties in attracting and retaining highly qualified staff who are "largely self-driven and job satisfaction oriented" (Feeny and Willcocks 1999, p.462).

Our interpretation of the interview data indicates that the way women talk about their work reinforces widely held impressions of the IT industry, but the use of structuration theory helps to show how this talk is not always consistent with the women's lived experiences. The women we interviewed had persisted in their pursuit of an IT career despite the problems they faced.

In order to understand better how women help configure the institutional realm of IT work, we propose that more qualitative studies of women at work in IT as well as women talking about IT are needed. It is suggested that a 'proper' application of structuration theory would require a longitudinal study. Due to the dynamic nature of the IT industry (unlike other, more traditional industries), a longitudinal study could give greater insight into perceptions of women in IT over time.

A limitation of the research so far is that it has relied on interviews and surveys with no data drawn from observation. Current research plans include the observation of women at work in project management and software process assessment teams. Our current research objectives are to continue to study the construction of female identities (Anthias 1999) and the question of gender differences in IT work and to apply the concepts of structuration theory to the data already collected from interviews and surveys of IT students and high school students and to collect new data from professional women.

\section{Acknowledgements}

The authors gratefully acknowledge financial support from the Australian Research Council Large Grants scheme which funded the collection of the interview data by the first two authors and Professor Eileen Trauth. The 
authors are also grateful to Professor Trauth for her collaboration with the WinIT project and for allowing access to her interview data. The authors also thank the IT professionals who agreed to be interviewed for this research.

\section{References}

1. Acker, J. (1990). "Hierarchies, jobs, bodies: a theory of gendered organisations", Gender and Society, 4 (2): 139-158.

2. Ahuja, M. K. (2002). "Women in the information technology profession: a literature review, synthesis and research agenda", European Journal of Information Systems, 11: 20-23.

3. Barrett, M. (1992). "Words and things: materialism and method in contemporary feminist analysis", Destabislising theory: contemporary feminist debates, M. A. Barrett and A. Phillips. Cambridge, Polity Press.

4. Beekhuyzen, J.P., Nielsen, S.H. and von Hellens, L. (2003a). "Challenging the Dualisms in Female Perceptions of IT Work", Proceedings of AusWIT03; Conference on Australian Women in IT, Awarded 'Best Paper', Hobart, Tasmania, (also to be published in the Australian Journal of Information Systems, May 2003).

5. Beekhuyzen, J.P., Nielsen, S.H. and von Hellens, L. (2003b). "Challenging the Dualisms in Female Perceptions of IT Work", Australian Journal of Information Systems, May 2003.

6. Boland, R. J. (1996). "Why shared meanings have no place in structuration theory: a reply to Scapens and Macintosh", Accounting, Organizations and Society, 21(7/8): 691-697.

7. Brosnan, M.J. \& Davidson, M.J. (1996) "Psychological gender issues in computing", Gender, Work and Organization, January 1996, 3(1): 13-25.

8. Burton, T (2002) New survey finds slight increase in IT workforce size, but demand softens for IT workers, ITAA.

9. Camp, T (1997) “The Incredible Shrinking Pipeline”, Communications of the ACM, 40 (10): 103-110.

10. Cohen, P. (1968). Modern social theory, London, Heinemann.

11. Council of Economic Advisors. (2000). "Opportunities and Gender Pay Equity in new Economic Occupations", Washington. Rep. Accessed: 11.12 .03 [online], http://clinton3.nara.gov.au/WH/EOP/CEA/html/whitepapers.html.

12. Encel, S. (1970). Equality and authority, London, Tavistock.

13. Fairclough, N. (1992a). Discourse and social change, Cambridge: Polity Press.

14. Fairclough, N. (1992b). "Discourse and text: Linguistic and intertextual analysis within discourse analysis", Discourse and Society, 3 (2), 193-217.

15. Fairclough, N. (1997). "Conversationalization of public discourse and the consumer", In R. Keat, N. Whiteley, \& N. Abercrombie (Eds.), The authority of the consumer (pp. 253-268). London: Routledge.

16. Feeny, D., and Willcocks, L.P. (1999) "Rethinking skills and capabilities in the information systems function", in W.L.Currie and B.Galliers, eds. Rethinking Management Information Systems, Oxford, OUP.

17. Freeman, P. and Aspray, W. (1999). "The Supply of Information Technology Workers in the United States", Computing Research Association, Washington, D.C.,

http://www.cra.org/reports/wits/chapter_7.html.

18. Gallivan, M. (2003) "Examining gender differences in IT professionals' perceptions of job stress in response to technological change", Proceedings of the 2003 ACM SIGMIS CPR Conference, April 10-12, 2003, pp 10-23.

19. Gewirtz,M. and A.Lindsey, (2001) Women in the new Economy, GLS Consulting.

20. Giddens, A. (1979). Central problems in social theory, Berkeley, University of California Press.

21. Giddens, A. (1982). Profiles and critiques in social theory, London, Macmillan.

22. Giddens, A. (1984). The constitution of society, Cambridge, Polity.

23. Giddens, A. ( 1991) Modernity and self identity: self and society in the late modern age, Cambridge, Polity Press.

24. Greenbaum, J. (1998) "The Times They are A'Changing: Dividing and Recombining Labour Through Computer Systems", in P. Thompson and C. Warhurst (eds.) Future Workplaces, Macmillan.

25. Greenhill, A., L. von Hellens, et al. (1997). Australian women in IT education: Meanings and multiculturalism, 6th International IFIP Conference on Women, Work and Computerization (WWC-97), Bonn, Germany.

26. Gürer, D. and Camp, T. (2002) Investigating the Incredible Shrinking Pipeline for Women in Computer Science, Final Report of the NSF Project 9812016. 
27. Halford, S. and P. Leonard (2001). Gender, power and organisations, London, Palgrave.

28. ITAA (Information Technology Association of America) (1998) Help Wanted: The IT Workforce Gap at the Dawn of a New Century, Information Technology Association of America, Arlington, VA.

29. Johnson, D.G., and K.W. Miller (2002). "Is Diversity in Computing a Moral Matter?", SICSCE Bulletin: Inroads - Paving the Way to Excellence in Computing Education, Special issue: Women in Computing, 34 (2) 9-10.

30. Jones, M. R. (1999). "Structuration theory", Rethinking management information systems, W. J. Currie and R. Galliers. Oxford, Oxford University Press: 103-135.

31. Klein, H., K and M. D. Myers (1999). "A set of principles for conducting and evaluating interpretive field studies in Information Systems", MIS Quarterly, 23(1): 67-93.

32. Lehmann, J. M. (1994). Durkheim and women, Lincoln, Nebraska University Press.

33. Megalogenis, G. (2003) "Women (not) on top". The Weekend Australian, April 26-27, p.17.

34. Meredyth, D. et al, (1999) "Real Time: Computers, Change and Schooling; National Sample Study of the IT Skills of Australian School Students", a project funded by the Commonwealth Department of Education, Training and Youth Affairs. http://www.detya.gov.au/archive/schools/Publications/1999/realtime.pdf.

35. META (2002) "IT staffing and compensation guide", META Consulting Group. http://www.metagroup.com/cgi-bin/inetcgi/jsp/home.do (cited in Gallivan 2003).

36. National Science Foundation (2000) Call for Proposals, NSF Initiative Focusing on the Underrepresentation of Women and Minorities in the IT Workforce, March 30.

37. Nielsen, S. H., L. von Hellens, R. Pringle, A.Greenhill (1999a). "Students' perceptions of Information Technology careers: Conceptualising the influence of cultural and gender factors for IT education", GATES, 5 (1): 30-38.

38. Nielsen, S.H., von Hellens, L.A., Greenhill, A., Halloran, P. \& Pringle, R. (1999b) "IT degree studies and skills development for learning organisations", Proceedings of the 1999 ACM SIGCPR Computer Personnel Research Conference,_New Orleans, USA, April 1999: 261-267.

39. Nielsen, S., von Hellens, L. and Wong, S. (2000) "The Women in Information Technology Project: Uncovering the Pride and Prejudices", Proceedings of the Sixth Australasian Women in Computing Workshop, Brisbane, July 2000.

40. Nielsen, S.H., von Hellens, L., Beekhuyzen, J.P. and Trauth, E. (2003). "Women talking about IT work: Duality or dualism?”, Proceedings of the ACM SIGCPR/SIGMIS, Philadelphia, USA, 10-12 April 2003.

41. $\quad$ Porter, E. (1991). Women and moral identity. Sydney, Allen and Unwin.

42. Pringle, R., S. H. Nielsen, L.von Hellens, A.Greenhill, L.Parfitt. (2000). "Net Gains: Successful strategies for Professional Women in IT", 7th International Conference on Women, Work and Computerization . Charting the Course to the Future, IFIP TC9 WG 9.1, Columbia, Canada.

43. QSR (1997). QSR NUD*IST 4: User Guide. Melbourne, Sage Publications.

44. Spender, D. (1995) Nattering on the Net; women, power and cyberspace, Spinifex Press, North Melbourne.

45. Trauth, E. (2002). "Odd girl out: an individual differences perspective on women in the IT profession", Information Technology and People, Vol. 15, No. 2, 2002: 98-118.

46. Trauth, E., S. H. Nielsen, von Hellens, L. (2000). Explaining the IT gender gap: Australian stories, 10th Australasian Conference on Information Systems, Brisbane, Australia.

47. Trauth, E., Nielsen, S.H. and von Hellens, L. (2003) "Explaining the IT gender gap: Australian stories for the new millennium", Journal of Research and Practice in Information Technology, Vol 35, No. 1, February 2003: 7-20.

48. Venkatesh, V., Morris, M.G., et al. (2000). “A Longitudinal field investigation of gender differences in indiviudal technology adoption in decision-making processes", Organizational Behavior and Human Decision Processes, (83): 33-60.

49. Venkatesh, V. and Morris, M.G. (2000) "Why Don't Men Ever Stop To Ask For Directions? Gender, Social Influence, And Their Role In Technology Acceptance And Usage Behaviour”, MIS Quarterly, 24, 1, $115-140$.

50. von Hellens, L.A., Nielsen, S.H. and Trauth, E. (2001). "Breaking and Entering the Male Domain: Women in the IT Industry", ACM SIGCPR Conference, San Diego.

51. von Hellens, L. A., Nielsen, S. H. and Beekhuyzen, J.P. (2003) "An Exploration of Dualisms in Female Perceptions of IT Work", Proceedings of the Informing Science Conference inSITE - Where Parallels Intersect,Pori, Finland, 24-27 June 2003: 1101-1112. 
52. von Hellens, L. A. and Nielsen, S.H. (2001). "Australian women in IT", Communications of the ACM, 44 (7): 46-52.

53. von Hellens, L. A., Pringle, R., Nielsen, S. and Greenhill, A. (2000). "People, business and IT skills: the Perspective of Women in the IT industry", ACM SIGCPR, Chicago, USA.

54. Walsham, G. and Han, C.K (1990). "Structuration theory and information systems research", International Conference on Information Systems.

55. Wardle, C., and Burton, L. (2000) "Programmatic efforts encouraging women to enter the Information Technology Workforce", SICSCE Bulletin: Inroads - Paving the Way to Excellence in Computing Education, Special issue: Women in Computing, 34 (2) 27-31.

Notes 